\section{NERC support \\ for UK geophysics not adequate}

SiR,- "Geophysics is a sub-division of geology". This comment was made by a representative of the UK Natural Environment Research Council (NERC) at the November Royal Astronomical Society meeting on how NERC supports geophysics in the UK. The comment probably revealed more about NERC's attitude to geophysics than all the numbers rained upon us.

$£ 6$ million, or $14 \%$ of NERC's annual budget, was spent, we were told, on geophysics. In the three relevant national institutes, the support for geophysics as a percentage of total expenditure is $19 \%$ at the Institute of Geological Sciences (IGS), $15 \%$ at the Institute of Oceanographic Sciences (IOS) and $35 \%$ at the British Antarctic Survey (BAS). Ten per cent of the $£ 6$ million was spent on geophysics in universities. Further, NERC supports eight research ships on which geophysics takes approximately $13 \%$ of the cost.

So an apparently convincing case can be made that support for geophysics is adequate. Most of the geophysics done in the NERC institutes and ships, however, is survey geophysics. In IGS and BAS it is a powerful tool to help the geologist--this is where the idea that geophysics is part of geology comes from (Nature 249, 794, 1974). In IOS, solid earth geophysics is the mapping of the occan floor. But geophysics is a much bigger subject than surveying the external layers of the earth. Geophysics is about ideas on the nature, origin, and evolution of the Earth and planets, and in this field we have shown that we can be international leaders-but for how long with NFRC's present policies?

Take one particular subdiscipline, palaeomagnetism. British scientists have led the way in creating this field which has brought about a revolution in Earth science. At present small groups at five universities are doing innovative work, fully competitive with work abroad, but they are starved of research students, and recently the Research Grants Committee decided that the all important instrument for the next decade's work, the cryogenic magnetometer $(£ 20,000)$, is to be shared between these centres. In comparison, vast sums of money are awarded whenever NERC's commitment to BAS or research vessels needs justification by university research activities. One may legitimately doubt if such projects would be funded to the extent they are on their fundamental scientific merits, but commitments are made, in the case of the BAS, for political reasons.

Nor is the problem simply at the research grant level. Instead of allotting a number of studentships to departments to distribute to those who show exceptional promise, all members of geo- science departments are now invited by NERC to put forward projects (described in three or four lines on the appropriate form). In awarding studentships, NERC selects projects thought most suitable for training, although the numerical distribution of studentships among departments follows an unchanging pattern. Thus the training awards committee for the geological sciences tells heads of departments which projects to put their research students on, without, of course, intimate knowledge of the department's research programme or of the prospective supervisors. Quite apart from this objectionable inroad into the independence of university departments to decide what courses are best for their students, the system continually throws up insoluble problems; a student wants to work with A, whose project this year has been turned down; nobody wants to work with B whose project has been approved.

The scheme is wisely not followed by SRC, but it doubtless gives NERC a chance to say in Whitehall that the universities are being guided into more 'relevant' research; indeed Dr Twinn of the council said at the meeting that university support is a 50-50 split between applied and pure. This shows a fundamental misunderstanding of the purpose of university research training; it is the intellectual challenge in a field which is relevant to the suitability of training.

Of the studentships awarded by the Committee, $14 \%$ are allotted to geophysics. This is not the right balance between a subject in which exciting developments have occurred and the more traditional field of geology. The Department of Geodesy and Geophysics at Cambridge has for as many years as I can remember been allotted two studentships yearly; so has my own department at Newcastle, which the university decided years ago to build up as a large centre of geophysical research. Many less internationally known geology departments receive three or four studentships and Imperial College Geology Department regularly gets over 12 . Thus members of the staff of my department have a very much poorer chance of supervising a research student than they would in these more traditionally minded departments.

But as geophysicists have been only a tiny minority on the research grants committee and only one pure geophysicist sits on the training awards committee (no geophysicist has been chairman of either) and as this pattern and the policy are self perpetuating and NERC headquarters seems cntirely satisfied, no change is likelv without open debate. In the National Science Foundation's solid earth division the support for geophysics, geochemistry and "traditional geology" is in the ratio of $2: 2: 1$ respectively.

Yours faithfully,

School of Physics,

S. K. RUNCORN

The University,

Newcastle upon Tyne, UK

\section{Tidal power schemes in Korea}

SiR,-While we debate tidal energy schemes in Britain, the Korean government intends to have a tidal power station in operation in Korea by 1986 . The group responsible for this is the Marine Science division of the Korean Research Institute for Ship and Ocean, previously known as KORDI (Nature, 254, 551).

The western coast of Korea is heavily indented with many large inlets. There are numerous off-shore islands and a tidal range of up to $10 \mathrm{~m}$. The country is mountainous with limited fossil-fuel resources and with most of its hydroelectric energy developed. It is heavily dependent on imported oil. A nuclear programme is also being implemented.

For tidal energy production there are several promising sites under examination and we recently visited one of these in Chung Nam province. During this visit we observed the construction of the Sap Kyo tidal barrier Asan-Gun. This is the thirc sea-arm closure to be made in this area since 1972 for land reclamation and water-resources schemes.

The Sap Kyo barrier is to be $3.4 \mathrm{~km}$ long, built in water depths of up to $18 \mathrm{~m}$, though the greater part of its length is in $8-12 \mathrm{~m}$ depths. The barrier is being constructed from rock, sand and earth-fill placed over a polyester and hessian bottom protection layer which in turn overlies a mean depth of $12 \mathrm{~m}$ of silt and sand. The maximum tidal range at the site exceeds $10 \mathrm{~m}$ and the impounded basin area exceeds $20 \mathrm{~km}^{2}$

The closure of the sea-arm is being undertaken by Korean contractors, without special construction methods such as cableways or float-in caissons, although the closure velocities will rise to $8 \mathrm{~ms}^{-1}$. The closure will be made next April, only 17 months after the start of the construction. Time for completion of the whole project, which includes a $12 \mathrm{~m}$ wide roadwav at $8.5 \mathrm{~m}$ above mean sea level and a sluicing structure $137 \mathrm{~m}$ long with six shell roller gates. is three years, at a cost of less than US \$30million.

The cost of this embankment is about US $\$ 9.000$ per $\mathrm{m}$ built at a rate of $3.1 \mathrm{~m}$ per day overall*. These are, of course, only approximate measures of performance, but they may be compared with recent estimates made for the Severn estuary closure-barrier of about US $\$ 300.000$ per $\mathrm{m}$ built at a rate of $2.1 \mathrm{~m}$ per day overall. The two schemes are not, of course, strictly comparable as the Severn closure-barrier has many concrete caissons incorporated in it. Nevertheless, if the Lavernock Point-Flat Holm section alone is considered, where the projects are roughly similar, the ratio of costs is still almost $6: 1$. Yours faithfully,

University of Cambridge, UK

F. GraY

University of Salford. UK E. M. WILSON

*All data from Korean government publications. 